\title{
Editorial
}

\section{LA INVESTIGACIÓN ODONTOLÓGICA DURANTE LA REVOLUCIÓN EDUCATIVA DEL ECUADOR}

La educación superior ha incidido durante décadas en el desarrollo de competencias, habilidades, destrezas y pensamiento crítico, marcando un notable incremento en el desarrollo de un país y mejorando notablemente la calidad de vida de sus habitantes. En el año 2007, el expresidente Rafael Correa lideró un proyecto denominado "Revolución Ciudadana", en cuyos objetivos y propuestas destacaba la denominada "Revolución Educativa". La misma estuvo orientada hacia la generación de nuevas y renovadas políticas en el ámbito de la educación superior, tales como: estructura jerárquica, un nuevo enfoque y estrategias de actividades académicas en el ámbito investigativo, gestión administrativa, vinculación con la comunidad y su incidencia en la actividad profesoral desde su perspectiva personal y social. ${ }^{1}$

La Asamblea Nacional Constituyente en Montecristi, Manabí presentó el 25 de julio de 2008 la nueva Constitución que fue redactada del 30 de noviembre de 2007 al 24 de julio del 2008, a partir de la cual surgió la Ley Orgánica de Educación Superior (LOES), y ésta a su vez dispuso que entidades como el Consejo de Evaluación, Acreditación y Aseguramiento de la Calidad de la Educación Superior (CEAACES), Consejo de Educación Superior (CES), Secretaria Nacional de Educación Superior, Ciencia y Tecnología (SENESCYT) sean las encargadas del proceso de Acreditación de las Universidades; dicho proceso exige cumplir a éstas entidades y a todo su personal ciertos parámetros para lograr una educación de calidad, como por ejemplo: una infraestructura adecuada que brinde todas las comodidades y servicios tanto para la docencia como para las prácticas que realizarán los estudiantes, docentes con títulos de cuarto nivel para impartir sus cátedras y proyectos de investigación orientados a ampliar los conocimientos y aplicarlos al servicio de la comunidad; es por esto que tomando en consideración este último aspecto en relación a la investigación surgió la iniciativa de realizar el Mapa Epidemiológico.

Dentro de este ámbito, la Universidad Católica de Cuenca ha propuesto y ejecutado numerosos proyectos de investigación en cada una de sus carreras y departamentos, iniciativas directamente relacionadas las necesidades del país y enmarcadas en las prioridades establecidas por el Estado Ecuatoriano. Es así como la Carrera de Odontología, en el marco de esta serie de

\footnotetext{
${ }^{1}$ Pacheco-Olea,L.A. Pacheco-Mendoza,Revolución de la Educación Superior en el Ecuador. La Revolución Educativa de la Universidad Ecuatoriana. Pacarina del Sur [En línea], año 6, núm. 23, abril-junio, 2015. ISSN: 2007-2309
} 
cambios en el sector educativo, promovió en el año 2016 la ejecución de un estudio de línea base, netamente descriptivo, denominado "Mapa Epidemiológico de Salud Bucal en Escolares de la ciudad de Cuenca (Provincia del Azuay)", cuyos objetivos claros estaban concentrados en determinar, predecir, cuantificar y proyectar el comportamiento de las enfermedades bucales de interés en Salud Pública. Adicionalmente, y como consecuencia directa de este estudio, se logró sensibilizar a toda la población encuestada acerca de la importancia de asistir a controles periódicos con el odontólogo o con un especialista en caso de ser necesario. En la actualidad, los miembros del personal docente y los estudiantes de Odontología llevan adelante una segunda experiencia de este tipo. Se trata del macro-proyecto de investigación acerca de las barreras que impiden el acceso a servicios de salud bucal, iniciativa que empieza a mostrar sus resultados a partir del año 2018.

El Proyecto Mapa Epidemiológico abarcó perspectivas clínicas y de autopercepción en diferentes grupos etarios de la población rural y urbana. En el ámbito clínico, se aplicaron índices de medición de caries, enfermedad periodontal, maloclusiones e higiene oral, mientras que en el ámbito de la autopercepción se realizaron encuestas de levantamiento epidemiológico. El proyecto contempló la participación de prácticamente todos los docentes de la carrera, quienes al ser especialistas de cuarto nivel permitieron que toda una promoción de alumnos en el año 2016 obtuviera su título de Odontólogo, mejorando además el ratio de egresos de la carrera. Gran parte de los trabajos publicados en el presente número de Odontología Activa son el resultado de las investigaciones realizadas en el marco de dicho proyecto de investigación epidemiológica, y de las tesis que del mismo se derivaron. En tal sentido, cabe recordar la frase célebre de John Ruskin, famoso escritor británico del siglo XIX, quien afirmó que "Educar a un joven no es hacerle aprender algo que no sabía, sino hacer de él alguien que no existía".

Para nuestro equipo editorial, es muy auspicioso el crecimiento de la revista Odontología Activa como órgano de difusión científica de la Carrera de Odontología, por tratarse de una plataforma que permite difundir trabajos científicos de calidad realizados por nuestros docentes y estudiantes. Todo esto se logra gracias al diseño y ejecución de macro-proyectos que la carrera lleva adelante, cuyos productos se verán reflejados en nuestra revista.

Alberto Leoncio Alvarado Cordero
Editor Técnico
María Cristina Alvear Córdova
Editor Asociado 